\title{
Childhood trauma is associated with a specific admixture of affective, anxiety, and psychosis symptoms cutting across traditional diagnostic boundaries
}

Citation for published version (APA):

van Nierop, M., Viechtbauer, W., Gunther, N., van Zelst, C., de Graaf, R., ten Have, M., van Dorsselaer, S., Bak, M., \& van Winkel, R. (2015). Childhood trauma is associated with a specific admixture of affective, anxiety, and psychosis symptoms cutting across traditional diagnostic boundaries. Psychological Medicine, 45(6), 1277-1288. https://doi.org/10.1017/S0033291714002372

Document status and date:

Published: 01/04/2015

DOI:

$10.1017 / \mathrm{S} 0033291714002372$

Document Version:

Publisher's PDF, also known as Version of record

Document license:

Taverne

Please check the document version of this publication:

- A submitted manuscript is the version of the article upon submission and before peer-review. There can be important differences between the submitted version and the official published version of record. People interested in the research are advised to contact the author for the final version of the publication, or visit the DOI to the publisher's website.

- The final author version and the galley proof are versions of the publication after peer review.

- The final published version features the final layout of the paper including the volume, issue and page numbers.

Link to publication

\footnotetext{
General rights rights.

- You may freely distribute the URL identifying the publication in the public portal. please follow below link for the End User Agreement:

www.umlib.nl/taverne-license

Take down policy

If you believe that this document breaches copyright please contact us at:

repository@maastrichtuniversity.nl

providing details and we will investigate your claim.
}

Copyright and moral rights for the publications made accessible in the public portal are retained by the authors and/or other copyright owners and it is a condition of accessing publications that users recognise and abide by the legal requirements associated with these

- Users may download and print one copy of any publication from the public portal for the purpose of private study or research.

- You may not further distribute the material or use it for any profit-making activity or commercial gain

If the publication is distributed under the terms of Article 25fa of the Dutch Copyright Act, indicated by the "Taverne" license above, 


\title{
Childhood trauma is associated with a specific admixture of affective, anxiety, and psychosis symptoms cutting across traditional diagnostic boundaries
}

\author{
M. van Nierop ${ }^{1 *}$, W. Viechtbauer ${ }^{1}$, N. Gunther ${ }^{2}$, C. van Zelst ${ }^{1}$, R. de Graaf ${ }^{3}$, M. ten Have ${ }^{3}$, S. van \\ Dorsselaer ${ }^{3}$, M. Bak ${ }^{1}$, Genetic Risk and OUtcome of Psychosis (GROUP) investigatorst and \\ R. van Winkel ${ }^{1,4}$ \\ ${ }^{1}$ Department of Psychiatry and Psychology, School for Mental Health and Neuroscience, EURON, Maastricht University Medical Centre, \\ Maastricht, The Netherlands \\ ${ }^{2}$ Faculty of Psychology and Educational Sciences, Open University, The Netherlands \\ ${ }^{3}$ Netherlands Institute of Mental Health and Addiction, Da Costakade, Utrecht, The Netherlands \\ ${ }^{4}$ University Psychiatric Center Katholieke Universiteit Leuven, Campus Kortenberg, Leuvensesteenweg, Kortenberg, Belgium
}

Background. Meta-analyses link childhood trauma to depression, mania, anxiety disorders, and psychosis. It is unclear, however, whether these outcomes truly represent distinct disorders following childhood trauma, or that childhood trauma is associated with admixtures of affective, psychotic, anxiety and manic psychopathology throughout life.

Method. We used data from a representative general population sample (NEMESIS-2, $n=6646$ ), of whom respectively 1577 and 1120 had a lifetime diagnosis of mood or anxiety disorder, as well as from a sample of patients with a diagnosis of schizophrenia (GROUP, $n=825$ ). Multinomial logistic regression was used to assess whether childhood trauma was more strongly associated with isolated affective/psychotic/anxiety/manic symptoms than with their admixture.

Results. In NEMESIS-2, largely comparable associations were found between childhood trauma and depression, mania, anxiety and psychosis. However, childhood trauma was considerably more strongly associated with their lifetime admixture. These results were confirmed in the patient samples, in which it was consistently found that patients with a history of childhood trauma were more likely to have a combination of multiple symptom domains compared to their nontraumatized counterparts. This pattern was also found in exposed individuals who did not meet criteria for a psychotic, affective or anxiety disorder and who did not seek help for subclinical psychopathology.

Conclusions. Childhood trauma increases the likelihood of a specific admixture of affective, anxiety and psychotic symptoms cutting across traditional diagnostic boundaries, and this admixture may already be present in the earliest stages of psychopathology. These findings may have significant aetiological, pathophysiological, diagnostic and clinical repercussions.

Received 22 April 2014; Revised 2 June 2014; Accepted 28 July 2014; First published online 2 October 2014

Key words: Anxiety, childhood trauma, depression, mania, psychosis, stratified medicine.

\section{Introduction}

Childhood trauma has been robustly associated with a number of mental disorders, including schizophrenia (Varese et al. 2012), depression (Nanni et al. 2012), anxiety (Kuo et al. 2011) and bipolar disorder (Etain et al. 2008). In a recent meta-analysis on the link between

\footnotetext{
* Address for correspondence: M. van Nierop, MSc, School of Mental Health and Neuroscience (MHeNS), Maastricht University Medical Centre, Vijverdalseweg 1, Concorde Building (SN2), 6200 MD Maastricht, The Netherlands.

(Email: m.vannierop@maastrichtuniversity.nl)

† The GROUP investigators are listed in the Appendix.
}

childhood trauma and schizophrenia in comparison to other disorders, Matheson et al. (2012) found no clear evidence that childhood trauma showed a stronger association with schizophrenia than with depression or bipolar disorder. The authors concluded that, instead of increasing risk for a specific disorder, childhood trauma may increase risk for stress-related disorders through changes of the hypothalamic-pituitary-adrenal axis, alterations of which have been reported in a number of mental disorders including psychosis (Read et al. 2014), depression (Vreeburg et al. 2009), anxiety (Elzinga et al. 2010) and mania (Valiengo et al. 2012).

While it is theoretically plausible that the assumed causal effect of childhood trauma would induce 
comparable biological alterations in different individuals, the issue why some individuals go on to develop depression, while others develop psychosis or mania, remains unresolved. A popular explanation is that one's individual genetic background may determine the expression of psychopathology after exposure to a harmful environmental factor (van Winkel et al. 2010). However, for childhood trauma, these models have not always been supported by the data at hand. For example, a number of studies found no evidence for an interaction between familial risk for psychosis and exposure to childhood trauma (Arseneault et al. 2011; Wigman et al. 2012; Fisher et al. 2014).

It has also been observed that the early stages of psychopathology are characterized by a mixed collection of symptoms not specific for any one mental disorder (van Os, 2013). Studies on high-risk individuals have also shown that predicting which individual is going to develop a particular disorder is extremely difficult (Fusar-Poli et al. 2014).

Taken together, these findings seem difficult to reconcile with the relatively simplistic notion that a person at above-average genetic risk for depression may develop an affective disorder following childhood trauma, whereas a person at higher genetic risk for schizophrenia would develop a psychotic outcome.

An alternative explanation is that childhood trauma may not specifically induce a particular disorder, but rather the co-occurrence of depression, psychosis, mania and anxiety over the life course. Depending on which symptoms prevail at any given point, diagnoses given to individual patients may then vary. Some research is available that reports associations between childhood trauma and clustering of multiple symptom domains, such as psychosis combined with depression (Smeets et al. 2012). If indeed childhood trauma is associated with the admixture of different symptom domains rather than specific mental disorders in individual patients, this would have important repercussions for the treatment of traumatized individuals presenting with mental symptoms (Read et al. 2007), as well as for aetiological models involving trauma-induced mental disorders (Read et al. 2005).

However, if evidence for trauma-related admixture is found, one could argue that a stronger association with the admixture of symptom domains may simply reflect increased severity in these individuals, as for example, when depressive symptoms become more severe, subjects may be more likely to also experience psychotic symptoms. A related hypothesis is that childhood trauma may initially give rise to affective symptoms, and only later to psychotic symptoms, which has been referred to as 'the affective pathway to psychosis' (Myin-Germeys \& van Os, 2007).
Therefore, the present study investigates whether childhood trauma is associated with specific isolated mental symptoms separately, or with the admixture of affective, anxious as well as psychotic symptoms in a representative, general population sample, with additional analyses investigating alternative hypotheses (increased severity of psychopathology and the affective pathway to psychosis). Moreover, the possible admixture of symptom domains following childhood trauma may have limited clinical relevance if it is only found in general population samples but not in clinical samples. Therefore, similar analyses were performed in a sample of patients with a lifetime mood disorder, a sample of patients with a lifetime anxiety disorder, and in a sample with a (non-affective) psychotic disorder.

\section{Methods}

\section{General population sample}

The second Netherlands Mental Health Survey and Incidence Study (NEMESIS-2)

The representative, general population sample forms part of NEMESIS-2, a longitudinal study of mental disorders in the Dutch general population. For the present study, the baseline and 3-year follow-up measurements were used. The study was approved by the Medical Ethics Review Committee for Institutions on Mental Health Care. Participants aged 18-65 years were included; insufficient fluency in Dutch was an exclusion criterion. Participants were interviewed by trained interviewers, who were not clinicians, with the Composite International Diagnostic Interview (CIDI) version 3.0 (De Graaf et al. 2008), and additional questionnaires. For a more detailed description of NEMESIS-2 methodology see De Graaf et al. (2010).

\section{Assessment of environmental factors}

Childhood trauma was assessed using a format based on the NEMESIS-1 trauma questionnaire (De Graaf et al. 2010). Whenever a subject reported having experienced one of five types of childhood trauma (emotional neglect, physical abuse, psychological abuse, sexual abuse and peer victimization; before the age of 16), they were asked to state how often it had occurred, on a scale with possible scores of 1 (once), 2 (sometimes), 3 (regularly), 4 (often), and 5 (very often). Factor analysis indicated that the five childhood trauma scales loaded onto one factor (eigenvalue 2.47); therefore one childhood trauma scale (range 0-25) was constructed consisting of the sum of the five childhood trauma types, in agreement with previous studies (van Nierop et al. 2014c). Cannabis use 
has been implicated in the development of various mental disorders (Moore et al. 2007) and may also be associated with childhood trauma (Harley et al. 2010). Therefore, analyses were repeated using cannabis use as a possible confounder. Cannabis use was assessed in the section Illegal Substance Use of CIDI 3.0. Subjects were asked to state whether they had ever (baseline) or in the previous 3 years (follow-up) used cannabis, and, if so, rated frequency of use in the period of most frequent use on a scale of 1 (less than once per month) to 6 (every day).

\section{Symptom domains}

Depressive, manic and anxiety symptoms were assessed with CIDI 3.0 (De Graaf et al. 2008). For depression, participants were asked if they ever had (at baseline) or in the time between baseline and followup experienced an episode lasting a number of consecutive days during which they felt low, depressed, or had a lack of interest. If endorsed, subjects were asked if, during this period, they had experienced any of a list of 28 depressive symptoms (see online Supplementary material).

For mania, subjects were asked whether they had experienced a period of several days of feeling increased excitement, energy or irritability at baseline (lifetime) or follow-up (incidence). If endorsed, they were asked if they experienced any of a list of 18 symptoms (see online Supplementary material).

Similarly, for anxiety, subjects were asked whether they had experienced a period in which they felt sudden attacks of anxiety or panic [section Panic disorder (PD)], increased worry or nervousness [section Generalized anxiety disorder (GAD)], or anxiety in social situations [section Social phobia (SP)], at baseline or follow-up. If endorsed, they were asked whether they had experienced any of a list of 16 (section PD), 12 (section GAD) or 15 (section SP) symptoms. All items were added to one anxiety scale (43 symptoms, see online supplementary material).

Last, presence of psychotic experiences was assessed using a questionnaire specifically developed, based on CIDI 1.1, for the purpose of assessing psychotic symptoms, since studies on earlier CIDI versions concluded that the instrument did not adequately measure psychotic symptoms (Andrew \& Peters, 1998). Participants were asked at baseline or follow-up whether they had experienced any of a list of 20 positive psychotic symptoms (see online supplementary material). As clinical relevance of psychotic experiences may be difficult to diagnose by lay interviewers (Helzer et al. 1985), individuals who endorsed at least one psychotic experience were contacted for re-interview over the telephone by an experienced clinician within 8 weeks after the initial interview, similar to the procedure in NEMESIS-1 (Bijl et al. 1998). Re-interviews were conducted using questions from the Structured Clinical Interview for DSM-IV (SCID-I), an instrument with proven reliability and validity in diagnosing psychotic disorders (Spitzer et al. 1992). Findings from all re-interviews were discussed with a second clinician (M.B.). For the present study, only the validated psychotic experiences, as established by re-interview, were used.

For each symptom category, symptoms were considered present when participants endorsed at least one symptom. All symptoms were assessed using 'yes' or 'no' questions, and for each symptom cluster sum scores were obtained by adding reported symptoms. If symptoms were endorsed, subjects were asked whether they had sought help for these symptoms.

\section{Sample and attrition}

A total of 6646 subjects participated at the baseline measurement, 5303 subjects participated at the 3-year follow-up measurement (Table 1). Baseline symptom scores did not differ between participants who were available for follow-up and participants who were not, except for psychosis; subjects lost to follow-up reported fewer psychosis symptoms at baseline (mean 0.07) than subjects available for follow-up (mean 0.12, $t=-2.7, p=0.006$ ). Subjects who did not participate in the follow-up measurement were slightly younger at baseline than subjects who were available

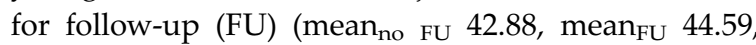
$t=-4.5, p<0.001)$. There were no differences in sex as a function of attrition.

\section{Patient samples}

From the NEMESIS-2 sample, two clinical samples were derived: a sample of participants with a mood disorder (major depressive disorder, bipolar disorder or dysthymia, $n=1577$ ) and a sample of participants with an anxiety disorder (social phobia, panic disorder or generalized anxiety disorder, $n=1120$ ). Diagnoses were established using CIDI 3.0. Since the number of patients with a non-affective psychotic disorder in NEMESIS-2 was too small $(n=43)$, we used data from an independent sample of patients with a psychotic disorder, the Genetic Risk and Outcome of Psychosis (GROUP) sample (Korver et al. 2012). In the GROUP study, patients with a diagnosis of non-affective psychotic disorder were recruited from five university hospitals in The Netherlands and Belgium (Groningen, Amsterdam, Maastricht, Utrecht, Louvain) and their affiliated mental healthcare institutions. Patients were eligible for inclusion if they: (1) were aged 16-65 years, (2) met the Diagnostic and Statistical Manual of Mental Disorders, Fourth Edition (DSM-IV) criteria for a non-affective psychotic 
Table 1. Baseline and first follow-up of NEMESIS-2 and GROUP: demographics and symptom profiles

\begin{tabular}{|c|c|c|}
\hline & Baseline & 3-year follow-up \\
\hline NEMESIS-2 & $(N=6646)$ & $(N=5303)$ \\
\hline Sex (male), $N(\%)$ & $2976(45)$ & $2381(45)$ \\
\hline No mood, anxiety or psychotic disorder, $N(\%)$ & $3986(63)$ & $3913(61)$ \\
\hline Age, years & $44.3(12.5)$ & $47.6(12.4)$ \\
\hline Childhood trauma $^{\mathrm{a}}$ & $1.7,0-25(3.2)$ & N.A. \\
\hline Depression symptom scale ${ }^{\mathrm{b}}$ & $4.0,0-28(7.3)$ & $1.50-28(5.0)$ \\
\hline Mania symptom scale ${ }^{\mathrm{b}}$ & $0.6,0-17(1.8)$ & $0.4,0-17(1.3)$ \\
\hline Anxiety symptom scale ${ }^{\mathrm{b}}$ & $4.9,0-34(6.7)$ & $1.5,0-34(3.8)$ \\
\hline Psychosis symptom scale ${ }^{c}$ & $0.1,0-17(0.6)$ & $0.1,0-17(0.4)$ \\
\hline Cannabis use $^{\mathrm{d}}$ & $0.4,0-6(1.1)$ & $0.03,0-6(0.3)$ \\
\hline Education level $^{\mathrm{e}}$ & $3.0,1-4(0.9)$ & $3.0,1-4(0.9)$ \\
\hline GROUP & $(N=825)$ & $(N=582)$ \\
\hline Sex (male), $N(\%)$ & $634(77)$ & $446(77)$ \\
\hline Age, years & $27.4,16-61(7.9)$ & $30.7,18-60(7.4)$ \\
\hline Childhood trauma ${ }^{\mathrm{f}}$ & $1.6,1-3.8(0.5)$ & N.A. \\
\hline Depression symptom scale & $2.4,1-7(1.5)$ & $1.9,1-7(1.2)$ \\
\hline Mania symptom scale ${ }^{\mathrm{h}}$ & $0.1,0-4(0.5)$ & $0.1,0-4(0.5)$ \\
\hline Anxiety symptom scale ${ }^{i}$ & $2.3,1-6(1.3)$ & $2.0,1-6(1.2)$ \\
\hline Psychosis symptom scale ${ }^{\mathrm{j}}$ & $1.8,1-5.3(0.8)$ & $1.6,1-4.1(0.7)$ \\
\hline Cannabis use $\mathrm{k}^{\mathrm{k}}$ & $1.7,0-3(1.4)$ & $0.7,0-3(1.2)$ \\
\hline Education level $^{1}$ & $4.1,0-8(2.1)$ & $4.4,0-8(2.1)$ \\
\hline
\end{tabular}

NEMESIS-2, The second Netherlands Mental Health Survey and Incidence Study; GROUP, Genetic Risk and Outcome of Psychosis study; N.A., not applicable.

Values given are mean, range (S.D.) unless otherwise stated.

${ }^{\text {a }}$ Childhood trauma (NEMESIS-2) is a combination scale of five different types of trauma: emotional neglect [0 (never) to 5 (very often)], psychological abuse (0-5), physical abuse (0-5), sexual abuse (0-5) and peer victimization (0-5).

${ }^{\mathrm{b}}$ Number of lifetime (baseline) or incident (past 3 years at follow-up) symptoms assessed with the Composite International Diagnostic Interview, version 3.0.

${ }^{\mathrm{c}}$ Number of lifetime (baseline) or incident (past 3 years at follow-up) clinically validated positive psychotic symptoms assessed with a self-constructed questionnaire.

${ }^{\mathrm{d}}$ Cannabis use (NEMESIS-2) was rated as frequency of use in the period of most frequent use on a scale of 0 (never) to 6 (every day), lifetime (baseline) and incident (past 3 years, follow-up).

${ }^{\mathrm{e}}$ Education level (NEMESIS-2): 1 (primary education), 2 (lower secondary education), 3 (higher secondary education), 4 (higher professional, university).

${ }^{\mathrm{f}}$ Childhood trauma (GROUP) is an average score of 25 items (physical, sexual and emotional abuse, and physical and emotional neglect) each ranging 1 (never true) to 5 (very often true).

${ }^{g}$ Severity of present state (past 2 weeks) depression assessed with the Positive and Negative Syndrome Scale (PANSS).

${ }^{\mathrm{h}}$ Severity of present state (past month) mania assessed with the Comprehensive Assessment of Symptoms and History instrument (CASH).

${ }^{i}$ Severity of present state (past 2 weeks) anxiety assessed with PANSS.

${ }^{\mathrm{j}}$ Severity of present state (past 2 weeks) psychosis assessed with PANSS.

${ }^{\mathrm{k}}$ Cannabis use (GROUP) rated as frequency of use in the period of most frequent use on a scale of 0 (never) to 3 (daily), lifetime (baseline) and incident (past 3 years, follow-up).

${ }^{1}$ Education level (GROUP); 0 (no education), 1 (primary school), 2-3 (secondary school), 4-5 (high school), 6 (lower vocational), 7 (higher vocational), 8 (university).

disorder [in Amsterdam, Maastricht, Utrecht and Louvain assessed with the Comprehensive Assessment of Symptoms and History (CASH; Andreasen et al. 1992); in Groningen with the Schedules for Clinical Assessment in Neuropsychiatry (SCAN 2.1; Wing et al. 1990)], (3) had first contact with mental healthcare $<10$ years before initial assessment, and (4) were proficient in Dutch. Participants were excluded if their estimated level of intelligence was below 70 .

Participants who were assessed at the Amsterdam, Maastricht, Utrecht and Louvain sites were used for the present study as we used symptom data from $\mathrm{CASH}$, which was not assessed at the Groningen site. Childhood trauma in the GROUP study was assessed 
with the Dutch version of the Childhood Trauma Questionnaire (CTQ-SF; Bernstein et al. 2003), a 25-item self-report questionnaire rated on a scale of 1 (never true) to 5 (very often true). The CTQ measures physical abuse, physical neglect, sexual abuse, emotional abuse and emotional neglect. A total trauma score was obtained by calculating the average of all 25 items. Symptom assessments in GROUP at baseline and follow-up included present state depression, anxiety and psychosis (positive psychotic symptoms) using the Positive and Negative Syndrome Scale (PANSS; Kay et al. 1987). Depression and anxiety were assessed with one item each (depression: have you felt sad, down or depressed; anxiety: worried, nervous, restless or panicked), on a scale of 1 (absent) to 7 (extreme), indicating severity of the symptom. Present state mania was assessed at baseline and follow-up with the CASH, with one item (have you felt overly or abnormally exited or active) on a scale of 0 (no) to 5 (severe). Cannabis use was assessed with the CIDI 2.1 (Andrew \& Peters, 1998). Subjects were asked to state whether they had ever (baseline) or in the previous 3 years (follow-up) used cannabis, and, if so, were rated on frequency of use in the period of most use on a scale of 1 (less than weekly) to 3 (daily).

\section{Sample}

In GROUP, 825 subjects participated at the baseline measurement, and 582 subjects were interviewed at the 3-year follow-up measurement. Subjects lost to follow-up did not differ from subjects who were available for follow-up in terms of age, sex, anxiety or mania symptom severity at baseline. Subjects lost to follow-up did, however, report a higher level of depressive symptoms $\left(\right.$ mean $_{\mathrm{no}} \mathrm{FU} 2.65$, mean $_{\mathrm{FU}} 2.36, t=$ 2.57, $p=0.011$ ) and psychosis symptoms (mean no FU 1.97, mean $_{\mathrm{FU}} 1.80, t=2.80, p=0.005$ ) at baseline.

\section{Analytical strategy}

All analyses were performed using Stata, version 12 (StataCorp, 2011). A priori confounders included in all analyses were age and sex.

\section{Associations of trauma with separate symptoms}

As a first step, it was assessed whether childhood trauma showed stronger associations with any of the symptoms using mixed-effects multilevel regression (XTMELOGIT in Stata) in the NEMESIS-2 sample. These models allow for a proper test for differences in the way to which trauma impacts on depression, mania, anxiety or psychosis. In other words, instead of analyzing the impact of childhood trauma on each symptom cluster separately, this method tests whether the impact of childhood trauma differs significantly between symptoms (van Nierop et al. 2014a). For each subject, four dichotomous outcomes were analysed, namely the presence of any depressive, manic, anxiety or psychotic symptom. Both the baseline and follow-up measurements were used, accounting for clustering within persons by including a random effect (intercept) at the subject level. Relevant effect sizes [i.e. ratios of odds ratios (RORs)] were obtained by post-hoc tests using the LINCOM command. For a more detailed description of this method see (van Nierop et al. 2014a). The analysis was repeated including cannabis use (Moore et al. 2007) and education level as possible confounders.

\section{Associations of trauma with multiple symptoms}

In order to investigate whether childhood trauma shows an increased likelihood of association with multiple symptom domains, rather than association with single symptom domains (e.g. association with depressive symptoms in isolation $v$. association with depressive symptoms co-occurring with symptoms of mania, psychosis or anxiety), multinomial logistic regression analyses (MLOGIT command in Stata) were performed, in the general population (NEMESIS-2) sample. The outcome variable consisted of eight categories: (1) no symptoms, (2) depression only, (3) mania only, (4) anxiety only, (5) psychosis only, (6) a combination of two symptom domains (any combination of depression, mania, anxiety or psychosis), (7) a combination of three symptom domains, (8) all four symptom domains combined. Both the baseline and follow-up measurements were used, while accounting for clustering within persons. Effect sizes were obtained by post-hoc tests using the LINCOM command. The analysis was repeated including cannabis use (Moore et al. 2007) and education level as possible confounders.

Similar analyses as described above were performed in a sample of patients with a lifetime mood disorder, a sample of patients with a lifetime anxiety disorder, and in a sample with a (non-affective) psychotic disorder, in order to examine the clinical relevance of reported findings.

\section{Alternative hypotheses to explain possible admixture}

Additional follow-up analyses addressed alternative hypotheses (increased severity or the affective pathway to psychosis) in two different ways. First, it was investigated whether the admixture of symptoms was a consequence of an increase in severity of psychopathology by repeating the analyses while controlling for symptom severity (e.g. associations of childhood trauma with depressive symptoms in isolation $v$. multiple symptoms, adjusted for number of depressive symptoms). A second follow-up analysis aimed to investigate the earliest 
Table 2. Baseline and first follow-up of NEMESIS-2. Associations of childhood trauma and presence of symptoms, and assessment of differences in strength of associations (e.g. whether trauma has a stronger association with one symptom over another)

\begin{tabular}{lllll}
\hline & Main effect, OR $(95 \% \mathrm{CI})^{\mathrm{a}}$ & $v$. depression, ROR $(95 \% \mathrm{CI})^{\mathrm{b}}$ & $v$. anxiety, ROR $(95 \% \mathrm{CI})$ & $v$. mania, ROR (95\% CI) \\
\hline Depression $^{\mathrm{c}}$ & $1.21^{* * *}(1.18-1.23)$ & & & \\
Anxiety $^{\mathrm{c}}$ & $1.18^{* * *}(1.16-1.21)$ & $0.99(0.97-1.01)$ & $1.01(0.99-1.03)$ & \\
Mania $^{\mathrm{c}}$ & $1.19^{* * *}(1.17-1.22)$ & $0.98(0.96-1.00)$ & $1.03^{*}(1.00-1.05)$ & $1.04^{* *}(1.01-1.06)$ \\
Psychosis $^{\mathrm{d}}$ & $1.23^{* * *}(1.20-1.26)$ & $1.02(0.99-1.04)$ & \\
\hline
\end{tabular}

NEMESIS-2, The second Netherlands Mental Health Survey and Incidence Study; ROR, ratio of odds ratios; CI, confidence interval.

All odds ratios (OR) are adjusted for age and sex. Childhood trauma is a combination scale of 0-25 of five different types of trauma: emotional neglect [0 (never) to 5 (very often)], psychological abuse (0-5), physical abuse (0-5), sexual abuse (0-5) and peer victimization (0-5). (Thus each OR corresponds with a 1-point increase in trauma.)

${ }^{a}$ Odds ratios express association of childhood trauma and presence of symptoms, other symptoms may be present.

${ }^{\mathrm{b}}$ Ratios of odds ratios express how much higher/lower the association between symptom and trauma was for each symptom-pair.

${ }^{c}$ Presence of any symptoms. The Composite International Diagnostic Interview, version 3.0 was used for the assessment of depressive, manic or anxiety (social phobia, generalized anxiety or panic disorder) symptoms. A self-constructed questionnaire was used for the assessment of positive psychotic symptoms (self-report).

${ }^{\mathrm{d}}$ Participants that self-reported psychotic symptoms were followed-up with an additional interview performed by a clinician for validation.

${ }^{*} p<0.05,{ }^{* *} p<0.01,{ }^{* * *} p<0.001$.

stages of psychopathology by repeating the analyses in a subsample of individuals who did not meet criteria for a psychotic, affective or anxiety disorder and did not seek help for their subclinical symptoms $(n=3986)$.

\section{Results}

\section{Associations of trauma with separate symptoms}

Table 2 shows the result of the analyses with separate symptoms (i.e. association of trauma with depression or mania or anxiety or psychosis, not necessarily in isolation). Childhood trauma was associated with all symptoms (left column), also after adding cannabis as a covariate (results not shown).

Childhood trauma did show a somewhat stronger association with psychosis than with mania [ROR $1.04,95 \%$ confidence interval (CI) 1.01-1.06, $p=0.006$ ] and anxiety (ROR 1.03, 95\% CI 1.00-1.05, $p=0.044$ ). However, in the other comparisons (depression $v$. all other symptoms, anxiety $v$. mania) no such differences were found (three right-hand columns). Adjusting for cannabis and education level did not significantly influence these results (results not shown).

\section{Associations of trauma with multiple symptoms}

\section{General population}

Analysis of the NEMESIS-2 sample revealed a pattern of significantly larger odds ratios (ORs) as more symptom clusters were present (Table 3 ). Thus, childhood trauma was consistently more strongly associated with combinations of symptom domains than with symptoms in isolation. Adjusting for symptom load, cannabis use and education level did not significantly influence these results. Fig. 1 shows the group sizes (\%) of subjects with isolated and co-occurring symptoms in the general population, divided by non-traumatized and traumatized subjects. Childhood trauma was included as a continuous measure throughout the different analyses but dichotomized for illustrative purposes at the 80th percentile, in accordance with previous work (Heins et al. 2011). In Fig. 1, a pattern of multiple symptom clusters in traumatized individuals (three right-hand black bars) rather than isolated symptoms (four left-hand black bars) is evident.

The pattern of admixture of symptoms associated with childhood trauma was confirmed in the sample of participants without a mood, anxiety, or psychotic disorder, and without help-seeking for mental symptoms (Table 3). Childhood trauma was associated with multiple rather than isolated symptoms of all domains. Adjusting for cannabis use and education level did not significantly influence these results (results not shown).

\section{Clinical samples}

The pattern of admixture of multiple symptom domains was also confirmed in the three clinical samples (Table 3). In mood disorder patients, childhood trauma was associated with an increased likelihood of combinations of symptom domains compared to 
Table 3. Baseline and first follow-up of NEMESIS-2. Associations of childhood trauma and isolated symptoms v. clustering of symptoms

\begin{tabular}{|c|c|c|c|c|c|c|}
\hline & $\begin{array}{l}\text { v. depression } \\
\text { ROR }(95 \% \mathrm{CI})^{\mathrm{a}}\end{array}$ & $\begin{array}{l}\text { v. mania } \\
\text { ROR }(95 \% \mathrm{CI})\end{array}$ & $\begin{array}{l}\text { v. anxiety } \\
\text { ROR }(95 \% \text { CI) }\end{array}$ & $\begin{array}{l}\text { v. psychosis } \\
\text { ROR }(95 \% \text { CI) }\end{array}$ & $\begin{array}{l}\text { v. } 2 \text { symptom domains } \\
\text { ROR }(95 \% \mathrm{CI})\end{array}$ & $\begin{array}{l}\text { v. } 3 \text { symptom domains } \\
\text { ROR }(95 \% \mathrm{CI})\end{array}$ \\
\hline \multicolumn{7}{|c|}{ General population sample (NEMESIS-2) } \\
\hline 2 symptom domains & $1.07^{* * *}(1.04-1.10)$ & $1.07^{*}(1.01-1.13)$ & $1.07^{* * *}(1.05-1.10)$ & $1.00(0.94-1.06)$ & & \\
\hline 3 symptom domains & $1.14^{* * *}(1.10-1.17)$ & $1.13^{* * *}(1.07-1.19)$ & $1.14^{* * *}(1.11-1.17)$ & $1.06(1.00-1.12)$ & $1.06^{* * *}(1.04-1.08)$ & \\
\hline 4 symptom domains & $1.25^{* * *}(1.21-1.30)$ & $1.25^{* * *}(1.17-1.32)$ & $1.26^{* * *}(1.21-1.30)$ & $1.17^{* * *}(1.10-1.24)$ & $1.17^{* * *}(1.14-1.20)$ & $1.10^{* * *}(1.08-1.13)$ \\
\hline \multicolumn{7}{|c|}{ Mood disorder patients (NEMESIS-2) ${ }^{\mathrm{b}}$} \\
\hline 2 symptom domains & $1.03(0.98-1.07)$ & & & & & \\
\hline 3 symptom domains & $1.08^{* *}(1.03-1.13)$ & & & & $1.05^{* * *}(1.03-1.08)$ & \\
\hline 4 symptom domains & $1.20^{* * *}(1.14-1.26)$ & & & & $1.17^{* * *}(1.12-1.21)$ & $1.11^{* * *}(1.07-1.15)$ \\
\hline \multicolumn{7}{|c|}{ Anxiety disorder patients (NEMESIS-2) ${ }^{\mathrm{b}}$} \\
\hline 2 symptom domains & & & $1.05(1.00-1.10)$ & & & \\
\hline 3 symptom domains & & & $1.08^{* *}(1.03-1.14)$ & & $1.03^{*}(1.00-1.06)$ & \\
\hline 4 symptom domains & & & $1.22^{* * *}(1.15-1.29)$ & & $1.16^{* * *}(1.11-1.21)$ & $1.12^{* * *}(1.08-1.17)$ \\
\hline \multicolumn{7}{|c|}{ Psychotic disorder patients (GROUP) ${ }^{\mathrm{c}}$} \\
\hline 2 symptom domains & $4.94^{* *}(1.96-12.43)$ & & $5.30^{* * *}(2.09-13.44)$ & $1.17(0.74-1.83)$ & & \\
\hline 3 symptom domains & $6.63^{* * *}(2.68-16.37)$ & & $7.12^{* * *}(2.83-17.92)$ & $1.57(0.99-2.48)$ & $1.34(0.98-1.85)$ & \\
\hline 4 symptom domains & $28.65^{* * *}(7.65-107.40)$ & & $30.78^{* * *}(8.11-116.79)$ & $6.77^{* * *}(2.38-19.25)$ & $5.80^{* * *}(2.17-15.52)$ & $4.32^{* *}(1.60-11.69)$ \\
\hline \multicolumn{7}{|c|}{ Non-diagnosed, non-help-seeking sample (NEMESIS-2) } \\
\hline 2 symptom domains & $1.06^{* *}(1.02-1.10)$ & $1.12^{* *}(1.03-1.21)$ & $1.04^{*}(1.01-1.08)$ & $0.99(0.92-1.07)$ & & \\
\hline 3 symptom domains & $1.11^{* * *}(1.06-1.16)$ & $1.17^{* * *}(1.07-1.27)$ & $1.09^{* * *}(1.04-1.13)$ & $1.03(0.96-1.11)$ & $1.04^{*}(1.01-1.08)$ & \\
\hline 4 symptom domains & $1.17^{* * *}(1.09-1.25)$ & $1.23^{* * *}(1.11-1.36)$ & $1.15^{* * *}(1.04-1.13)$ & $1.09(0.99-1.20)$ & $1.10^{* *}(1.03-1.17)$ & $1.06(0.99-1.13)$ \\
\hline
\end{tabular}

NEMESIS-2, The second Netherlands Mental Health Survey and Incidence Study; GROUP, Genetic Risk and Outcome of Psychosis study; ROR, ratio of odds ratios; CI, confidence interval.

All effect sizes are adjusted for age and sex.

a Post-hoc estimation analyses: e.g. ROR of the association of childhood trauma and depressive symptoms in isolation $v$. combination of any two, three or all four symptoms.

${ }^{b}$ In NEMESIS-2, lifetime symptoms are assessed, thus in the 'mood disorder' group, no participants exist with only mania, anxiety or psychosis symptoms; in the 'anxiety disorder' group no participants exist with only depression, mania or psychosis.

${ }^{\mathrm{c}}$ In GROUP, present state symptoms are assessed, thus participants are present with only depression or only anxiety (and no psychosis). No participants reported mania only.

${ }^{*} p<0.05,{ }^{* *} p<0.01,{ }^{* * *} p<0.001$. 


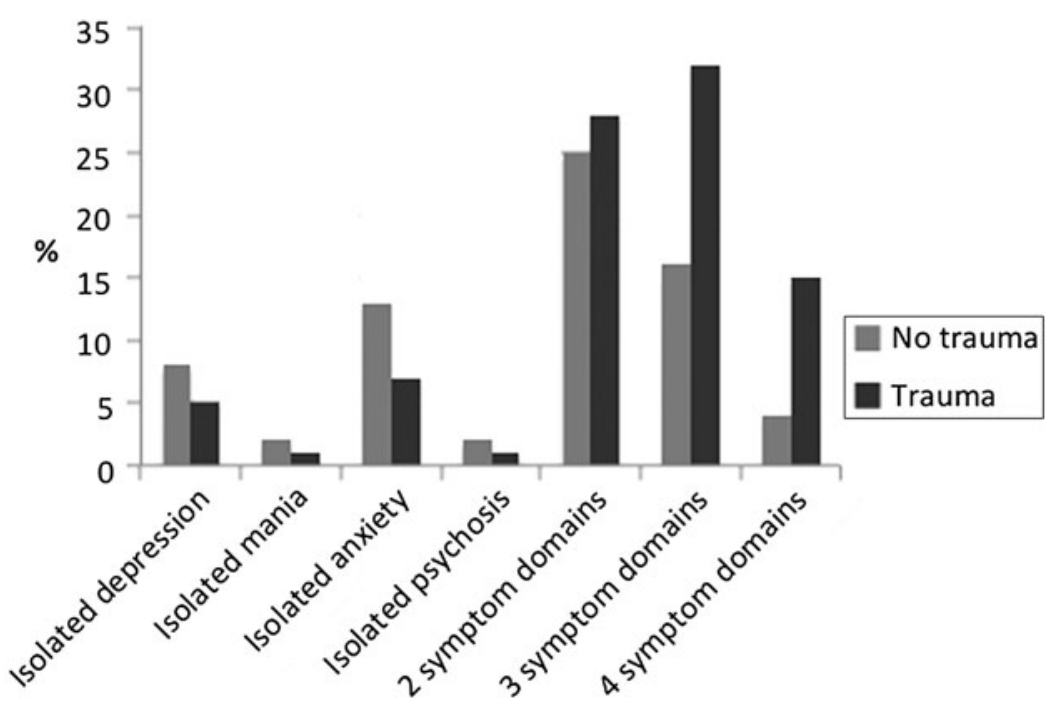

Fig. 1. Group sizes (\%) of isolated and co-occurring symptoms in non-traumautized and traumautized subjects in the general population (NEMESIS-2). The childhood trauma score was dichotomized at the 80th percentile for illustrative purposes. Traumatized individuals tend to report multiple symptoms (three right-hand black bars) rather than isolated symptoms (four right-hand black bars).

depression in isolation. Results were similar when patients with bipolar disorder were excluded. Similarly, in anxiety disorder, traumatized patients showed an increased likelihood of multiple symptom clusters, compared to anxiety symptoms in isolation.

In the psychotic disorder sample, childhood trauma also showed an increased likelihood of multiple symptom domains, compared to depression, anxiety or psychosis in isolation. In all three clinical samples, adjusting for cannabis use and education level did not significantly influence these results (results not shown).

\section{Discussion}

\section{Findings}

In a general population sample, childhood trauma was associated with four major mental symptom domains: depression, mania, anxiety and psychosis. The strengths of these associations were similar, except for a somewhat stronger association with psychosis than with anxiety and mania, indicating a central role for reality distortion following childhood trauma, especially since sensitivity analyses suggested that psychotic symptoms are not the 'end-product' of severe affective dysregulation, but rather an integral part of psychopathology following childhood trauma, already present in the earliest stages of psychopathology. Importantly, childhood trauma was associated with multiple symptom clusters rather than with isolated symptoms. As more symptom clusters were combined (i.e. two, three or four symptom clusters) the ORs of the association with childhood trauma became significantly larger. The robustness of this pattern of admixture was noteworthy, not affected by controlling for symptom severity, and evident also in the sample of participants specifically selected for the absence of help-seeking or a clinical (anxiety, mood or psychotic) disorder. Moreover, the pattern of admixture was consistently found in three different clinical samples.

\section{Why is this important?}

Biological psychiatry aims to understand the pathophysiology of mental disorders. Despite considerable research efforts, however, insights into the origins of mental illness are still limited. Reasons for the limited success may be found in the lack of a biologically informed diagnostic system ('the missing gold standard'), significance chasing with underpowered studies, approximate replications, and extreme comparisons between patients and (super)healthy controls, rather than focusing on clinically relevant subgroups (Kapur et al. 2012). Kapur and colleagues have recently argued that the application of 'stratified medicine' in psychiatry may provide an interesting option to advance our understanding of mental illness. That is: focusing on clinically meaningful differences between homogeneous clinical subtypes across traditional diagnostic categories rather than hypothesis-rejection v. controls (Kapur et al. 2012). In their paper, this approach is illustrated with an example from the field of oncology: overexpression of human growth factor subtype (HER2) in breast cancer tissue was first identified as a form of breast cancer with a poor prognosis. Using a stratified medicine approach, overexpression of HER2 was later identified in subtypes of several 
types of cancer. Development of specific therapies considerably increased survival for all these subtypes and now HER2 stratification serves as an important guide for treatment (Kapur et al. 2012).

In this paper, we adopted an environmental stratification approach, showing a specific pattern of symptom admixture across a range of different populations, at the subclinical as well as at the clinical level. These findings may have significant aetiological, pathophysiological, diagnostic and clinical repercussion. At the level of aetiology, our results strongly support a causal role of childhood trauma in the development of multiple psychiatric disorders, given the specificity of the pattern of admixture of symptoms that was strongly linked to childhood trauma exposure across multiple diagnostic categories.

In addition, these findings should also inform research strategies, as the present results suggest that future work should examine the long-term consequences of childhood trauma across multiple diagnostic domains, rather than focusing on traditional diagnostic categories, in order to elucidate the biological and psychological mechanisms underlying the transition from a subclinical admixture of symptoms, to helpseeking, and finally a given clinical disorder. One could infer considerable interplay between the implicated symptom domains (van Os, 2013), resulting in patterns of psychopathology that are increasingly specific to the individual as symptoms become more severe, and finally result in a diagnosis that to a large degree will depend on which symptoms prevail at that particular point in time (Wigman et al. 2013). In addition to significant aetiological and research implications, these findings should also inform treatment, and possibly, diagnostic decisions. While the exact clinical implications are as yet unclear, active enquiry and diagnostic attention to multiple symptom domains is warranted, rather than only for the domain that is most prominent at the time of presentation. Moreover, once these findings are independently replicated, and further refined in terms of which specific affective, psychotic and anxiety symptoms are involved, it may be argued that these findings should have direct diagnostic repercussions. Finally, the findings also suggest that treatment of traumatic experiences should be considered irrespective of diagnosis, even though this is not always current practice (De Bont et al. 2013). Last, development of therapeutic approaches, tailored specifically at individuals exposed to severe childhood traumatic experiences, should be made a priority.

\section{Strengths and limitations}

The current findings should be interpreted in terms of its strengths and limitations. Childhood trauma was assessed by subjective retrospective report, therefore recall bias may have influenced these results, although research suggests good reliability of retrospective assessment of childhood trauma (Fisher et al. 2011). Childhood trauma was assessed using different questionnaires in the NEMESIS-2 and GROUP studies, thereby diminishing comparability between these samples. However, as the main focus of this study was the investigation of the association between trauma and symptoms, and not the comparison of different groups in terms of trauma history, this limitation is unlikely to affect the validity of the reported findings. As in earlier studies using these samples no clear evidence was found to support differential psychopathological outcomes depending on different childhood traumatic experiences (van Nierop et al. 2014a, b), the different types of trauma were grouped to one trauma scale, however additional studies may be warranted investigating differential effects of separate trauma types in more detail. Additionally, a more detailed investigation of gender differences may be warranted in future studies (Fisher et al. 2009). Even though the baseline and first follow-up measurements of NEMESIS-2 were used, the analyses performed used these measurements as cross-sectional data, since the incidence of novel symptoms in this sample was too low to allow for prospective analyses. Therefore, the present study does not allow to fully address the developmental model suggested by the cross-sectional analyses. However, by performing the various sensitivity analyses in separate subsamples at different stages of psychopathology, we were able to address at least part of this issue. Lifetime presence of symptoms was assessed, precluding assessment of simultaneously occurring symptoms. However, this study aimed to assess development of symptoms over the lifetime rather than at the same point in time, making the assessment of simultaneously occurring symptoms unnecessary.

A further limitation is that we did not have comprehensive data on (complex) post-traumatic stress disorder, borderline personality disorder or dissociative disorder, disorders that are also associated with childhood trauma. Future research should incorporate these disorders as well; however, they are known for their prominent mixture of affective and anxiety symptoms, and psychotic symptoms are often described as well, so we would argue that our findings may also extend to these disorders.

Strengths of this study are the multiple and large samples as well as the representativeness of the samples, increasing the generalizability of these results. By incorporating symptom assessments across diagnostic boundaries this study adds important and more comprehensive evidence to psychiatric research 
focused on the sequelae of traumatic experiences. Last, assessment of symptoms was conducted by trained clinical interviewers in the GROUP study and all reports of psychotic symptoms in the larger NEMESIS-2 study were validated by clinicians, thus increasing reliability compared to self-report measures of particularly psychosis.

In conclusion, these findings provide evidence for childhood trauma as a major risk factor for psychopathology, characterized by an admixture of affective, anxiety and psychotic symptoms, which may already be present at the earliest stages of psychopathology.

\section{Appendix. GROUP investigators}

Richard Bruggeman and Durk Wiersma, Department of Psychiatry, University Medical Center Groningen, Groningen, The Netherlands; Wiepke Cahn and Rene S. Kahn, Department of Psychiatry, University Medical Center Utrecht, Rudolf Magnus Institute of Neuroscience, Utrecht, The Netherlands; Lieuwe de Haan and Carin J. Meijer, Department of Psychiatry, Academic Medical Centre, University of Amsterdam, Amsterdam, The Netherlands; Inez Myin-Germeys, Department of Psychiatry and Psychology, School for Mental Health and Neuroscience, EURON, Maastricht University Medical Centre, PO Box 616 (Vijv1), Maastricht, The Netherlands; Jim van Os, Department of Psychiatry and Psychology, School for Mental Health and Neuroscience, EURON, Maastricht University Medical Centre, PO Box 616 (Vijv1), Maastricht, The Netherlands and Department of Psychosis Studies, King's College London, King's Health Partners, Institute of Psychiatry, London, UK.

\section{Supplementary material}

For supplementary material accompanying this paper visit http://dx.doi.org/10.1017/S0033291714002372.

\section{Acknowledgements}

This work was supported by the Ministry of Health, Welfare and Sports (grant no. 310253); with supplement support from The Netherlands Organization for Health Research and Development (ZonMw). Supported by the European Community's Seventh Framework Program under grant agreement no. HEALTH-F2-2009-241909 (Project EU-GEI).

\section{Declaration of Interest}

None.

\section{References}

Andreasen NC, Flaum M, Arndt S (1992). The comprehensive assessment of symptoms and history (CASH). An instrument for assessing diagnosis and psychopathology. Archives of General Psychiatry 49, 615-623.

Andrew G, Peters L (1998). The psychometric properties of the Composite International Diagnostic Interview. Social Psychiatry and Psychiatric Epidemiology 33, 80-88.

Arseneault L, Cannon M, Fisher H, Polanczyk G, Moffitt TE, Caspi A (2011). Childhood trauma and children's emerging psychotic symptoms: a genetically sensitive longitudinal cohort study. American Journal of Psychiatry 168, 65-72.

Bernstein DP, Stein JA, Newcomb MD, Walker E, Pogge D, Ahluvalia T, Stokes J, Handelsman L, Medrano M, Desmond D (2003). Development and validation of a brief screening version of the Childhood Trauma Questionnaire. Child Abuse \& Neglect 27, 169-190.

Bijl RV, van Zessen G, Ravelli A, de Rijk C, Langendoen Y (1998). The Netherlands Mental Health Survey and Incidence Study (NEMESIS): objectives and design. Social Psychiatry and Psychiatric Epidemiology 33, 581-586.

De Bont PA, van den Berg DP, van der Vleugel BM, De Roos C, Mulder CL, Becker ES, de Jongh A, van der Gaag M, van Minnen A (2013). A multi-site single blind clinical study to compare the effects of prolonged exposure, eye movement desensitization and reprocessing and waiting list on patients with a current diagnosis of psychosis and co morbid post traumatic stress disorder: study protocol for the randomized controlled trial Treating Trauma in Psychosis. Trials 14, Published online: 23 May 2013. doi:10.1186/1745-6215-14-151.

De Graaf R, Ormel J, Ten Have M, Burger $H$, Buist-Bouwman M (2008). Mental disorders and service use in the Netherlands. Results from the European Study of the Epidemiology of Mental Disorders (ESEMeD). In The WHO World Mental Health Surveys: Global Perspectives on the Epidemiology of Mental Disorders (ed. R. C. Kessler and T. Bedirhan Ustun), pp. 388-405. Cambridge University Press: Geneva, Switzerland.

De Graaf R, ten Have M, van Dorsselaer S (2010). The Netherlands Mental Health Survey and Incidence study-2 (NEMESIS-2): design and methods. International Journal of Methods in Psychiatric Research 19, 125-141.

Elzinga BM, Spinhoven P, Berretty E, de Jong P, Roelofs K (2010). The role of childhood abuse in HPA-axis reactivity in social anxiety disorder: a pilot study. Biological Psychiatry 83, 1-6.

Etain B, Henry R, Bellivier F, Mathieu F, Leboyer M (2008). Beyond genetics: childhood affective trauma in bipolar disorder. Bipolar Disorders 10, 867-876.

Fisher H, McGuffin P, Boydell J, Fearon P, Craig TK, Dazzan P, Morgan K, Doody GA, Jones PB, Leff J, Murray RM, Morgan C (2014). Interplay between childhood physical abuse and familial risk in the onset of psychotic disorders. Schizophrenia Bulletin. Published online: 7 January 2014. doi:10.1093/schbul/sbt201.

Fisher H, Morgan C, Dazzan P, Craig TK, Morgan K, Hutchinson G, Jones PB, Doody GA, Pariante C, McGuffin P, Murray RM, Leff J, Fearon P (2009). 
Gender differences in the association between childhood abuse and psychosis. British Journal of Psychiatry 194, 319-325.

Fisher HL, Craig TK, Fearon P, Morgan K, Dazzan P, Lappin J, Hutchinson G, Doody GA, Jones PB, McGuffin P, Murray RM, Leff J, Morgan C (2011). Reliability and comparability of psychosis patients' retrospective reports of childhood abuse. Schizophrenia Bulletin 37, 546-553.

Fusar-Poli P, Yung AR, McGorry P, van Os J (2014). Lessons learned from the psychosis high-risk state: towards a general staging model of prodromal intervention. Psychological Medicine 44, 17-24.

Harley M, Kelleher I, Clarke M, Lynch F, Arseneault L, Connor D, Fitzpatrick C, Cannon M (2010). Cannabis use and childhood trauma interact additively to increase the risk of psychotic symptoms in adolescence. Psychological Medicine 40, 1627-1634.

Heins M, Simons C, Lataster T, Pfeifer S, Versmissen D, Lardinois M, Marcelis M, Delespaul P, Krabbendam L, van Os J, Myin-Germeys I (2011). Childhood trauma and psychosis: a case-control and case-sibling comparison across different levels of genetic liability, psychopathology, and type of trauma. American Journal of Psychiatry 168, 1286-1294.

Helzer JE, Robins LN, McEvoy LT, Spitznagel EL, Stoltzman RK, Farmer A, Brockington IF (1985). Physician reexamination of lay-interviewed cases in the general population. Archives of General Psychiatry 42, 657-666.

Kapur S, Phillips AG, Insel TR (2012). Why has it taken so long for biological psychiatry to develop clinical tests and what to do about it? Molecular Psychiatry 17, 1174-1179.

Kay SR, Fiszbein A, Opler LA (1987). The positive and negative syndrome scale (PANSS) for schizophrenia. Schizophrenia Bulletin 13, 261-276.

Korver N, Quee PJ, Boos HB, Simons C, de Haan L (2012). Genetic Risk and Outcome of Psychosis (GROUP), a multi site longitudinal cohort study focused on gene-environment interaction: objectives, sample characteristics, recruitment and assessment methods. International Journal of Methods in Psychiatric Research 21, 205-221.

Kuo JR, Goldin PR, Werner K, Heimberg RG, Gross JJ (2011). Childhood trauma and current psychological functioning in adults with social anxiety disorder. Journal of Anxiety Disorders 25, 467-473.

Matheson SL, Shepherd AM, Pinchbeck RM, Laurens KR, Carr VJ (2012). Childhood adversity in schizophrenia: a systematic meta-analysis. Psychological Medicine 43, 225-238.

Moore THM, Zammit S, Lingford-Hughes A, Barnes TRE, Jones PB, Burke M, Lewis G (2007). Cannabis use and risk of psychotic or affective mental health outcomes: a systematic review. Lancet 370, 319-328.

Myin-Germeys I, van Os J (2007). Stress-reactivity in psychosis: evidence for an affective pathway to psychosis. Clinical Psychology Review 27, 409-424.

Nanni V, Uher R, Danese A (2012). Childhood maltreatment predicts unfavorable course of illness and treatment outcome in depression: a meta-analysis. American Journal of Psychiatry 169, 141-151.

Read J, Fosse R, Moskowitz A, Perry B (2014). The traumagenic neurodevelopmental model of psychosis revisited. Neuropsychiatry 4, 65-79.

Read J, Hammersley P, Rudegeair T (2007). Why, when and how to ask about childhood abuse. Advances in Psychiatric Treatment 13, 101-110.

Read J, van Os J, Morrison AP, Ross CA (2005). Childhood trauma, psychosis and schizophrenia: a literature review with theoretical and clinical implications. Acta Psychiatrica Scandinavia 112, 330-350.

Smeets F, Lataster T, Dominguez MG, Hommes J, Lieb R, Wittchen HU, van Os J (2012). Evidence that onset of psychosis in the population reflects early hallucinatory experiences that through environmental risks and affective dysregulation become complicated by delusions. Schizophrenia Bulletin 38, 531-542.

Spitzer RL, Williams JB, Gibbon M, First MB (1992). The Structured Clinical Interview for DSM-III-R (SCID). I: history, rationale, and description. Archives of General Psychiatry 49, 624-629.

Statacorp (2011). Stata Statistical Software: Release 12. StataCorp LP: College Station, TX.

Valiengo LL, Soeiro-de-Souza MG, Marques AH, Moreno DH, Juruena MF, Andreazza AC, Gattaz WF, Machado-Vieira R (2012). Plasma cortisol in first episode drug-naive mania: differential levels in euphoric verus irritable mood. Journal of Affective Disorders 138, 149-152.

van Nierop M, Lataster T, Smeets F, Gunther N, van Zelst C, de Graaf R, ten Have M, van Dorsselaer S, Bak M, Myin-Germeys I, Viechtbauer W, van Os J, van Winkel R (2014a). Psychopathological mechanisms linking childhood traumatic experiences to risk of psychotic symptoms. Analysis of a large, representative population-based sample. Schizophrenia Bulletin 40, S123-S130.

van Nierop M, van Dam D, Viechtbauer W, Velthorst E, van Winkel R, GROUP Investigators (2014b). Childhood abuse and neglect in relation to presence and persistence of psychotic and depressive symptomatology. Psychological Medicine (in press).

van Nierop M, van Os J, Gunther N, van Zelst C, de Graaf $R$, ten Have $M$, van Dorsselaer S, Bak M, Myin-Germeys I, van Winkel R (2014c). Does Social Defeat mediate the association between childhood trauma and psychosis? Evidence from the Nemesis-2 study. Acta Psychiatrica Scandinavia 129, 467-476.

van Os J (2013). The dynamics of subthreshold psychopathology: implications for diagnosis and treatment. American Journal of Psychiatry 170, 695-698.

van Winkel R, Esquivel G, Kenis G, Wichers M, Collip D, Peerbooms O, Rutten BPF, Myin-Germeys I, van Os J (2010). Genome-wide findings in schizophrenia and the role of gene-environment interplay. CNS Neuroscience \& Therapeutics 16, 5-e192.

Varese F, Smeets F, Drukker M, Lieverse R, Lataster T, Viechtbauer W, Read J, Van Os J, Bentall R (2012). Childhood adversities increase the risk of psychosis: a meta-analysis of patient-control, prospective- and 
cross-sectional cohort studies. Schizophrenia Bulletin 38, 661-671.

Vreeburg SA, Hoogendijk WJG, van Pelt J, DeRijk RH, Verhagen JCM, van Dyck R, Smit JH, Zitman FG, Penninx BWJH (2009). Major depressive disorder and hypothalamic-pituitary-adrenal axis activity. Results from a large cohort study. Archives of General Psychiatry 66, 617-626.

Wigman JTW, van Os J, Thiery E, Derom C, Collip D, Jacobs N, Wichers M (2013). Psychiatric diagnosis revisited: towards a system of staging and profiling combining nomothetic and idiographic parameters of momentary mental states. PLoS ONE 8, e59559.

Wigman JTW, Van Winkel R, Ormel J, Verhulst FC, Van Os J, Vollebergh WAM (2012). Early trauma and familial risk in the development of the extended psychosis phenotype in adolescence. Acta Psychiatrica Scandinavia 126, 266-273.

Wing JK, Babor T, Brugha T, Burke J, Cooper JE, Giel R, Jablenski A, Regier D, Sartorius N (1990). SCAN.

Schedules for clinical assessment in neuropsychiatry. Archives of General Psychiatry 47, 589-593. 